\title{
British Society of Restorative Dentistry Conference
}

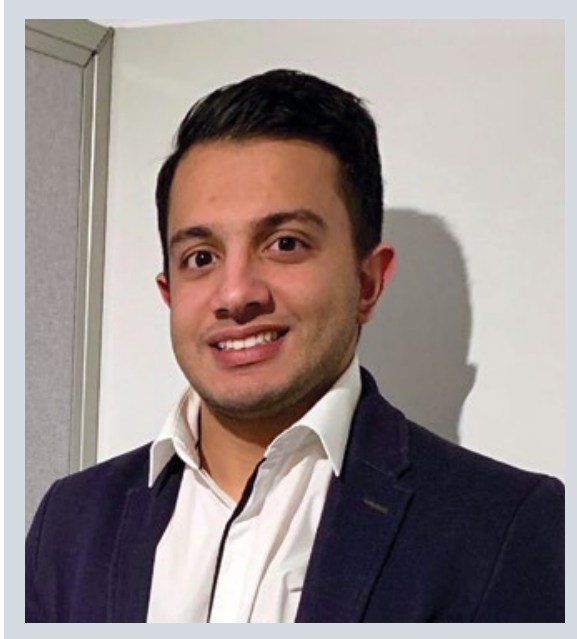

A. S. Araghi

The annual scientific meeting for the British Society of Restorative Dentistry took place on 5-6 April 2019 at the Science Gallery London. 'Past experiences future decisions' was the theme across the two days. The society had put together a great line-up touching on all aspects of restorative dentistry.

The conference started by providing advice for junior trainees on how to enter the speciality training programme and what can be expected on the five-year journey through to the exit exam. It was reassuring to see that such a prestigious society facilitates for its most junior trainees alongside experienced clinicians and academics.

As the day progressed we were given lectures regarding the rehabilitation of the oral cancer patient and what the latest advances are in this region of practice. While prosthetic rehabilitation was the mainstay of treatment in years gone by, 3D guided hard and soft tissue reconstruction with implant prostheses is now the way forward.

Furthermore, we learnt about the mental well-being of patients with a facial deformity and the importance of the clinical psychologist in the multidisciplinary management of this select group of patients - an eye-opening talk which has most definitely changed my perception and will inform my future clinical practice.

The second day was presentation day for trainees and a vast array of exceptional posters were on display. From clinical audit and protocol to restorative treatment and research, it was reassuring to see so many trainees that are committed to the speciality at such an early stage of their careers. It was a real honour to present my poster presentation at such a prestigious event!

A highlight of the second day was the advances and research being carried out on $3 \mathrm{D}$ guided endodontic treatment and how the outcomes were being monitored. The speaker enlightened the audience on the use of $3 \mathrm{D}$ access cavity stents that were printed from preoperative $\mathrm{CBCT}$ scanning at a safe radiation dose - the research unit is seeing very favourable endodontic outcomes in high complexity teeth, making future practice safer and more efficient.

I would like to thank the society for putting together an educationally rich, academically exciting and friendly conference. I look forward to engaging with the society more and would encourage all to attend future meetings.

By A. S. Araghi, OMFS DCT1, North Manchester

General Hospital, UK

\section{Death notice: Maurice Parker}

Maurice Parker, who qualified from Leeds in 1951, passed away on 30 March 2019 at the Bradford Royal Infirmary from the frailties of old age, aged 91.

After National Service where he attained the rank of captain in the RADC and service with BAOR, Maurice spent some years in private practice latterly at Allerton, Bradford before spending the rest of his career with the Bradford school dental service. Profoundly missed by his only son, Edward Maurice.

Edward would be happy to hear from anyone who has memories of his father. He can be contacted on parvulescued@ hotmail.com.

\section{New WHO Collaborating Centre at UCL}

The University College London (UCL)

Dental Public Health Group based within the Department of Epidemiology and Public Health has been designated a World Health Organisation (WHO) Collaborating Centre for Oral Health Inequalities and Public Health. The UCL team will be working with colleagues at the WHO Headquarters in Geneva supporting the preparation of the forthcoming Global Oral Health Report.

Professor Richard Watt, Director of the new WHO Collaborating Centre, said:

'This is a very exciting opportunity for our group to become more involved in supporting WHO global policy on oral health inequalities and is recognition of our research and policy work over the last 30 years.'

Dr Benoit Varenne, Responsible Officer at WHO Headquarters, welcomed the announcement: 'I am delighted that the UCL Dental Public Health Group have now officially been designated as a WHO Collaborating Centre and look forward to working with Professor Watt and his colleagues in addressing the significant burden of oral diseases in different regions of the world.'

The research agenda of the UCL Dental Public Health Group has focused on exploring the underlying determinants of oral health inequalities and evaluating community interventions to promote better oral health. The Group has a global network of research collaborators and is heavily involved in supporting policy through their work with Public Health England and other agencies.

Further information about the UCL Dental Public Health Group can be found at www.ucl.ac.uk/dph. 